Annuaire du Collège de France 2017-2018

\title{
Génétique moléculaire (1993-2003)
}

\section{Pierre Chambon}

\section{OpenEdition}

\section{Journals}

Édition électronique

URL : https://journals.openedition.org/annuaire-cdf/16056

DOI : 10.4000/annuaire-cdf. 16056

ISBN : 978-2-7226-0572-5

ISSN : 2109-9227

Éditeur

Collège de France

Édition imprimée

Date de publication : 30 décembre 2020

Pagination : 627

ISBN : 978-2-7226-0516-9

ISSN : 0069-5580

Référence électronique

Pierre Chambon, « Génétique moléculaire (1993-2003) », L'annuaire du Collège de France [En ligne], 118 2020, mis en ligne le 01 avril 2021, consulté le 22 août 2022. URL : http://journals.openedition.org/ annuaire-cdf/16056 ; DOI : https://doi.org/10.4000/annuaire-cdf.16056 


\title{
GÉNÉTIQUE MOLÉCULAIRE (1993-2003)
}

\author{
Pierre CHAMBON \\ Membre de l'Institut (Académie des sciences), professeur émérite
}

\section{RECHERCHE ET PUBLICATIONS}

Durant l'année académique 2017-2018, nous avons poursuivi nos recherches dans la droite ligne de nos travaux antérieurs (voir rapport précédent) dans le cadre de travaux effectués à l'IGBMC avec l'aide du CNRS, de l'Inserm et de l'Usias (Institut d'études avancées de l'université de Strasbourg, chaire de biologie et de génétique moléculaire), et de travaux effectués et publiés en collaboration avec des groupes de recherche extérieurs français et étrangers.

\section{Travaux effectués dans notre laboratoire}

GANTI K.P., MukHERJI A., SurJit M., Li M. et CHAMBON P., « Similarities and differences in the transcriptional control of expression of the mouse TSLP gene in skin epidermis and intestinal epithelium », Proc. Natl. Acad. Sci. USA, vol. 114, n 6, 2017, p. E951-E960, DOI : 10.1073/pnas.1620697114.

\section{Travaux en collaboration avec des groupes de recherche extérieurs}

Kim K., Goldberg I.J., Graham M.J., Sundaram M., Bertaggia E., LeE S.X., Qiang L., Haeusler R.A., Metzger D., Chambon P., Yao Z., Ginsberg H.N. et Pajvani U.B., « $\gamma$-secretase Inhibition lowers plasma triglyceride-rich lipoproteins by stabilizing the LDL receptor », Cell. Metab., vol. 27, no 4, 2018, p. 816-827.e4, DOI : 10.1016/j.cmet.2018.02.010.

Malhotra N., Leyva-Castillo J.M., Jadhav U., Barreiro O., Kam C., O’Neill N.K., Meylan F., Chambon P., von Andrian U.H., Siegel R.M., WANG E.C., Shivdasani R. et GEHA R.S., «ROR $\alpha$-expressing T regulatory cells restrain allergic skin inflammation », Sci. Immunol., vol. 3, nº 21, 2018, pii: eaao6923, DOI : 10.1126/sciimmunol.aao6923.

Andersson A., Törnqvist A.E., Moverare-Skrtic S., Bernardi A.I., FARMAn H.H., Chambon P., Engdahl C., Lagerquist M.K., Windahl S.H., Carlsten H., Ohlsson C. et ISLANDER U., « Roles of activating functions 1 and 2 of estrogen receptor $\alpha$ in lymphopoiesis », J. Endocrinol., vol. 236, no 2, 2018, p. 99-109, DOI : 10.1530/JOE-17-0372.

Vieira J.M., Howard S., Villa Del Campo C., Bollini S., Dubé K.N., Masters M., Barnette D.N., Rohling M., Sun X., Hankins L.E., Gavriouchkina D., Williams R., Metzger D., Chambon P., Sauka-Spengler T., Davies B. et Riley P.R., «BRG1-SWI/ SNF-dependent regulation of the Wt1 transcriptional landscape mediates epicardial activity during heart development and disease », Nat. Commun., vol. 8, 2017, p. 16034, DOI : 10.1038/ ncomms 16034 .

Arnal J.F., Lenfant F., Metivier R., Flouriot G., Henrion D., Adlanmerini M., Fontaine C., Gourdy P., Chambon P., KAtZenellenbogen B. et KATZEnellenbogen J., «Membrane and nuclear estrogen receptor alpha actions: From tissue specificity to medical implications », Physiol. Rev., vol. 97, $n^{\mathrm{o}}$ 3, 2017, p. 1045-1087, DOI : 10.1152/ physrev.00024.2016. Review. 